\title{
XAB2 functions in mitotic cell cycle progression via transcriptional regulation of CENPE
}

\author{
Shuai Hou ${ }^{\star, 1,4}, \mathrm{Na} \mathrm{Li}^{2,4}$, Qian Zhang ${ }^{1}$, Hui Li ${ }^{1}$, Xinyue Wei ${ }^{1}$, Tian Hao ${ }^{1}$, Yue Li ${ }^{3}$, Sikandar Azam¹, Caigang Liü ${ }^{3}$, Wei Cheng ${ }^{1}$, Bilian Jin ${ }^{1}$, \\ Quentin Liu', Man Li ${ }^{*}, 2$ and Haixin Lei, ${ }^{*, 1,2}$
}

Xeroderma pigmentosum group $A(X P A)$-binding protein 2 (XAB2) is a multi-functional protein that plays critical role in processes including transcription, transcription-coupled DNA repair, pre-mRNA splicing, homologous recombination and mRNA export. Microarray analysis on gene expression in XAB2 knockdown cells reveals that many genes with significant change in expression function in mitotic cell cycle regulation. Fluorescence-activated cell scanner analysis confirmed XAB2 depletion led to cell arrest in G2/M phase, mostly at prophase or prometaphase. Live cell imaging further disclosed that XAB2 knockdown induced severe mitotic defects including chromosome misalignment and defects in segregation, leading to mitotic arrest, mitotic catastrophe and subsequent cell death. Among top genes down-regulated by XAB2 depletion is mitotic motor protein centrosome-associated protein E (CENPE). Knockdown CENPE showed similar phenotypes to loss of XAB2, but CENPE knockdown followed by XAB2 depletion did not further enhance cell cycle arrest. Luciferase assay on CENPE promoter showed that overexpression of XAB2 increased luciferase activity, whereas XAB2 depletion resulted in striking reduction of luciferase activity. Further mapping revealed a region in CENPE promoter that is required for the transcriptional regulation by XAB2. Moreover, ChIP assay showed that XAB2 interacted with CENPE promoter. Together, these results support a novel function of XAB2 in mitotic cell cycle regulation, which is partially mediated by transcription regulation on CENPE.

Cell Death and Disease (2016) 7, e2409; doi:10.1038/cddis.2016.313; published online 13 October 2016

Xeroderma pigmentosum group A (XPA)-binding protein 2 (XAB2) is a highly conserved gene, which was originally identified in human as a protein interacting with XPA using yeast two-hybrid system. ${ }^{1}$ The human XAB2 gene is located on chromosome 19p13.2, encoding a protein of 855 amino acids with molecular weight of $100 \mathrm{kDa}$. The XAB2 protein contains 15 tetratricopeptide repeat motifs involved in protein-protein interactions and the assembly of multiprotein complexes. It has many orthologues, such as SYF1 in Saccharomyces cerevisiae ${ }^{2,3}$ ATH55 in rat ${ }^{4}$ and Fandango in Drosophila. ${ }^{5}$

It was reported that XAB2 could interact with Cockayne syndrome group $A$ and $B$ (CSA and CSB) proteins as well as RNA polymerase II, and downregulation of XAB2 using antiXAB2 antibody or siRNA both specifically inhibited normal RNA synthesis and the recovery of RNA synthesis after UV irradiation, indicating that $\mathrm{XAB} 2$ is involved in transcription and transcriptioncoupled DNA repair. ${ }^{1,6}$ Further studies showed that XAB2 might bind to hyperphosphorylated form of RNA polymerase II in a UV- and CSA/CSB-dependent manner ${ }^{7}$ and contribute to transcription elongation. ${ }^{6}$ Furthermore, XAB2 is implicated as a component of Prp19/XAB2 complex ${ }^{6}$ (hAquarius, XAB2, Prp19, CCDC16, hISY1 and PPIE) or Prp19/CDC5L-related complex ${ }^{8}$ required for pre-mRNA splicing. During splicing, Prp19 complex is recruited to the spliceosome and crucial for spliceosome activation by stabilizing U5 and U6 with the spliceosome after U4 dissociation., ${ }^{9,10}$ In Hela cells, Prp19/ $X A B 2$ complex was reported to associate with RNA rather than DNA, and knockdown of XAB2 would inhibit Bcl-x pre-mRNA splicing. ${ }^{6}$ Similarly, SYF1, homolog of XAB2 in yeast, is also identified as a factor involved in pre-mRNA splicing, ${ }^{2,3}$ and a novel transcription elongation factor by linking Prp19 complex with RNA polymerase II through its $C$ terminal domain. ${ }^{11}$

$\mathrm{XAB2}$ is also essential for early mouse embryogenesis, because knockdown of XAB2 in mice has been shown to lead to embryonic lethality. ${ }^{12}$ It was previously demonstrated that XAB2 could interact with retinoic acid receptor $A$ and histone deacetylase 3 , and $X A B 2$ deficiency increased all-trans retinoic acid (ATRA)-induced cellular differentiation in ATRA-sensitive and -resistant cancer cells. These results suggest that XAB2 may display an inhibitory effect in ATRA-induced cellular differentiation. ${ }^{13}$ Furthermore, XAB2 may play a role in tumorigenesis. XAB2 expression is significantly downregulated in primary gastric cancer, ${ }^{14}$ triple-negative breast cancer ${ }^{15}$ and a long-term survivor of an atypical teratoid/rhabdoid tumour, ${ }^{16}$ while it is upregulated in ovarian cancer ${ }^{17}$ and sarcoma ${ }^{18}$ using Oncomine database (www.oncomine.org). The XAB2 tagSNPs

\footnotetext{
${ }^{1}$ Institute of Cancer Stem Cell, Cancer Center, Dalian Medical University, Dalian, China; ${ }^{2}$ Department of Oncology, Second Affiliated Hospital, Institute of Cancer Stem Cell, Dalian Medical University, Dalian, China and ${ }^{3}$ Breast Disease and Reconstruction Center, Breast Cancer Key Lab of Dalian, Second Affiliated Hospital, Dalian Medical University, Dalian, China

*Corresponding author: S Hou or M Li or H Lei, Institute of Cancer Stem Cell, Cancer Center, Dalian Medical University, 9 West Section, Lvshun South Rd, Dalian, 116044 , China. Tel: +8641186110494, Fax:+8641186110509; E-mail: houshuai@dmu.edu.cn or liman126126@163.com or haixinlei@dmu.edu.cn

${ }^{4}$ These authors contributed equally to this work.

Abbreviations: XPA, xeroderma pigmentosum group A; XAB2, XPA-binding protein 2; CSA, Cockayne syndrome group A; ATRA, all-trans retinoic acid; CENPE, centrosome-associated protein E; FACS, fluorescence-activated cell scanner; $\gamma$-H2A.X, Phospho-Histone H2A.X; ChIP, chromatin immunoprecipitation; s.d., standard deviation

Received 14.7.16; revised 05.9.16; accepted 05.9.16; Edited by R Aqeilan
} 
a

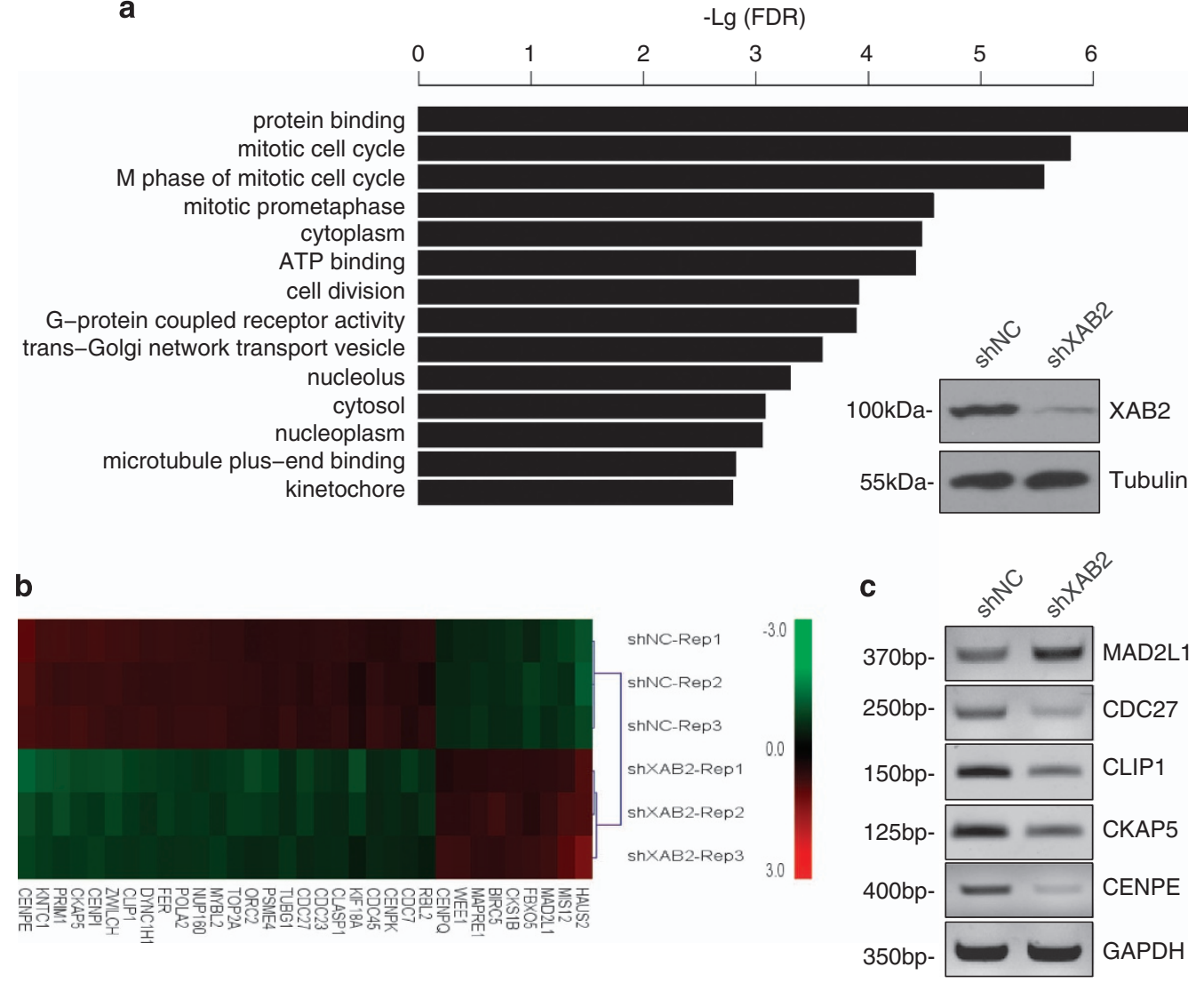

Figure 1 Microarray analysis reveals genes involved in cell cycle and mitotic progression as major genes with expression changes after XAB2 knockdown. (a) Gene Ontology analysis showing gene functions with significant changes in expression after XAB2 knockdown. Right-bottom panel: western blot showing XAB2 was efficiently depleted after cells were infected with lentivirus containing XAB2 shRNA. (b) Differential expression of genes ( $>2$-fold, $P<0.05$ ) related to cell cycle and mitotic progression after XAB2 knockdown. (c) RT-PCR analysis validated gene expression levels after XAB2 knockdown

(rs794078 and rs4134816) are dramatically correlated with the risk of non-small cell lung cancer in Chinese population. ${ }^{19}$ In addition, XAB2 levels are strikingly reduced in aged hematopoietic stem cells, suggesting a role in ageing. ${ }^{20}$ Recently, we showed that XAB2 presented in the ribonucleo-protein of a consensus element found in naturally intronless mRNAs that can promote mRNA export, and disruption of XAB2 led to nuclear retention of the intronless $m R N A s$, suggesting a role of $\mathrm{XAB2}$ in naturally intronless mRNA export. ${ }^{21}$ Most recently, $\mathrm{XAB2}$ has been reported to regulate the end resection step during homologous recombination repair of chromosomal double-strand breaks. ${ }^{22}$ Thus, XAB2 is an important multifunctional protein.

Despite the critical functions of XAB2 in gene expression, the downstream target genes and the subsequent physiological roles in human cells are still unknown. Here, we perform microarray analysis on Hela cells transfected with XAB2 shRNA, revealing that $X A B 2$ modulates the expression of a significant number of genes, most highly involved in cell cycle and mitotic progression. We further show that XAB2 knockdown causes chromosome misalignment and missegregation, abnormal nuclear structure, spindle pole, and microtubule organization, leading to mitotic arrest, mitotic catastrophe and subsequent cell death. Mechanistic analysis reveals that the phenotype observed in XAB2 depletion cells is mediated by a kinesin-like motor protein called centrosome-associated protein $E$ (CENPE), the transcription of which is regulated by $\mathrm{XAB}$ 2. Taken together, our data indicate that $\mathrm{XAB} 2$ regulates mitotic progression by transcription control of CENPE.

\section{Results}

Microarray analysis reveals that XAB2 knockdown results in aberrant expression of many genes involved in mitotic cell cycle. Previous studies indicated that XAB2 is a multifunctional protein that plays critical role in transcription, ${ }^{6}$ splicing ${ }^{6}$ and mRNA export. ${ }^{21}$ To identify target genes regulated by XAB2, gene expression of XAB2 depleted HeLa cells was analysed by microarray. This analysis revealed that a total of 690 genes showed significant change in expression ( $>2$-fold, $P<0.05$ ). Among them, 216 genes were up-regulated and 474 genes were downregulated (Supplementary Table 1). The knockdown efficiency of XAB2 was confirmed by western blot (Figure 1a) at protein level as well as by microarray at mRNA level (Supplementary Table 1, down-regulated 3.43-fold). To verify microarray data, RT-PCR was used to check the expression 
level of several genes including MAPK4, SERPINB5, EPGN and PRG4. Consistent with the microarray results, reduced expression of these four genes was confirmed by RT-PCR (Supplementary Figure S1).

Next, Gene Ontology analysis was performed to analyse the biological functions of the 690 genes with altered expression. As shown in Figure 1a, several top functions affected were related to cell cycle regulation, including mitotic cell cycle, $\mathrm{M}$ phase of mitotic cell cycle, mitotic prometaphase and cell division. Accordingly, a set of genes involved in the regulation of cell cycle were deregulated (Figure 1b), including CENPE, CKAP5, CLIP1, CDC27 and Mad2L1, the expression of which were validated by RT-PCR (Figure 1c). Together, these data suggested a critical role of XAB2 in mitosis and cell cycle regulation.

XAB2 knockdown leads to mitotic arrest, mitotic catastrophe and cell death. To further investigate whether $\mathrm{XAB} 2$ regulates cell cycle and mitotic progression, fluorescence-activated cell scanner (FACS) analysis was performed on Hela cells transfected with XAB2 shRNA. Strikingly, XAB2 knockdown resulted in a significant increase of cells arrested in G2/M phase $(32.8 \%$ in XAB2 shRNA transfected cells compared to $10.6 \%$ in control, $P<0.001$, Figures $2 a$ and $b$ ). In order to rule out off-target effects of XAB2 shRNA, another shRNA and two siRNAs were tested for their effects on cell cycle. Similarly, knockdown XAB2 using different shRNA or siRNA resulted in significant cell cycle arrest at G2/M phase in both Hela (Supplementary Figure S2A) and 293T cells (Supplementary Figure S2B), indicating cell cycle arrest is a major defect after XAB2 depletion. Consistently, the expression of mitotic markers Cyclin B1 and Phospho-HistoneH3 (Ser10) was apparently increased in XAB2 knockdown cells by western blot (Figure 2c) and FACS analysis (Supplementary Figure S2C).

Next, XAB2 knockdown cells and control cells were stained with antibody against tubulin and DAPI, significant mitotic cells arrested at prophase and prometaphase were observed in cells with XAB2 depletion (82.8 versus $15.1 \%$ in control, $P<0.001$, Figures $2 \mathrm{~d}$ and $\mathrm{e})$, further supporting of severe defects in mitotic cell cycle progression.

To better investigate the function of XAB2 on mitotic progression, we depleted XAB2 in HeLa cells stably expressing GFP-H2B and tracked mitosis using live cell imaging. As shown in Figure 2f, two daughter nuclei were separated by $50 \mathrm{~min}$ and mitosis was completed by $70 \mathrm{~min}$ in control cells. In contrast, nuclei separation was not observed even by $300 \mathrm{~min}$ in XAB2 depleted cells. Statistic analysis further revealed that the average mitosis duration time from nuclear envelope breakdown to anaphase was prolonged from $\sim 60 \mathrm{~min}$ in control cells to 290 min in cells with XAB2 depletion (Figure $2 \mathrm{~g}$, $P<0.001)$. The percentage of cells showing mitotic arrest or mitotic delay (mitosis duration $>90 \mathrm{~min}$ ) was raised dramatically from 4.9 to $81.2 \%$ (Figure $2 \mathrm{~h}, P<0.001$ ). Furthermore, cells undergoing mitotic cell death were significantly increased after XAB2 knockdown from 3.9 to $65.8 \%$ (Figure 2i, $P<0.001)$. To further test whether XAB2 knockdown induced cell death after mitotic catastrophe, FACS analysis was performed after annexin $\mathrm{V}$ and propidium iodide $(\mathrm{PI})$ staining. As shown in Figures $2 \mathrm{j}$ and $\mathrm{k}$, the percentage of annexin
V-positive cells was obviously increased in XAB2 knockdown cells from 5.8 to $24.7 \%$, suggesting significant cell death after XAB2 depletion. Taken together, these data indicated that $\mathrm{XAB} 2$ deficiency resulted in mitotic arrest, mitotic catastrophe and cell death.

XAB2 knockdown causes chromosome alignment and segregation defects. Because mitosis requires a tight control of chromosome movement, we next performed DAPI staining to determine whether XAB2 affects chromosome alignment and segregation. This analysis revealed severe chromosome misalignment at equatorial plate and internuclear DNA bridges (Figure 3a).

Consistent with previous observation, most of the mitotic cells showed mitotic arrest, mitotic delay or segregation defect. Specifically, mitotic arrest in prophase or prometaphase with defects in chromosome alignment was observed in $43.1 \%$ of mitotic cells after XAB2 depletion compared to $2.6 \%$ in control, which did not divide and eventually led to cell death (Figures $3 \mathrm{~b}$ and c). Mitotic delay was observed in $33.2 \%$ of mitotic cells after XAB2 knockdown versus $4.2 \%$ in control, these cells were still able to divide after a mitotic delay with chromosome misalignment, but also with chromosome segregation defect resulting in the formation of internuclear DNA bridges (Figures 3b and c). Whereas segregation defect without chromosome misalignment was also observed in $16.3 \%$ of mitotic cells as a comparison to $6.9 \%$ in control (Figures $3 \mathrm{~b}$ and $\mathrm{c}$ ). Both cells of mitotic delay or segregation defect showed abnormal nuclear structure and died in cell cycle progression (Figure $3 \mathrm{~b}$ ). These data indicated severe defects in chromosome alignment and segregation after XAB2 knockdown.

XAB2 deficiency induces abnormal spindle pole, nuclear structure and microtubule organization and DNA breaks. We next sought to further examine how mitosis is disturbed in XAB2 knockdown cells. First, spindle pole was checked in XAB2 depleted cells since correct spindle formation is required for chromosome alignment and segregation. Strikingly, single or multiple spindle poles was observed in $\sim 30$ and $\sim 8 \%$ of prophase/prometaphase cells after XAB2 knockdown using either tubulin or Aurora A staining (Figures $4 \mathrm{a}$ and b). Second, abnormal nuclear structures including nuclear bubs, peanut shape or irregular nucleus were observed in most of interphase cells after XAB2 depletion (Figure 4c). Meanwhile, microtubule organization was also severely disrupted. Clustered irregular assembly of microtubules was observed at one side of nucleus as compared to an even distribution in control cells (Figure 4c). Third, DNA damages in XAB2 knockdown cells were examined since nuclear bubs are generally associated with DNA breaks. ${ }^{23,24}$ As shown in Figures $4 d$ and $e$, the expression of DNA damage marker Phospho-Histone H2A.X $(\gamma-\mathrm{H} 2 \mathrm{~A} . \mathrm{X})$ was significantly increased in XAB2 knockdown cells by both immunofluorescence staining and western blot analysis. Together, these data suggested that XAB2 was critical for microtubule and spindle organization as well as genome stability. 
Defects in mitotic progression in XAB2 depletion cells are mediated by CENPE. We next set out to explore the mechanism on how XAB2 regulates mitosis. We noticed that
CENPE, a key factor in mitosis, was among the top genes down-regulated in XAB2 knockdown microarray results. Therefore, we tested the hypothesis that $X A B 2$ regulates a

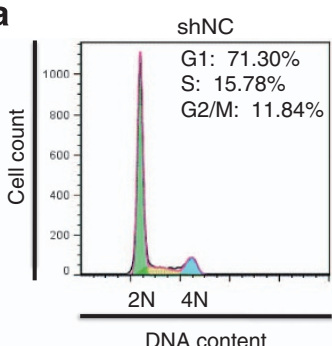

c

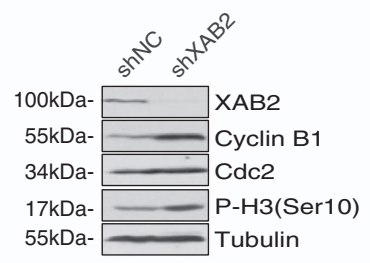

e

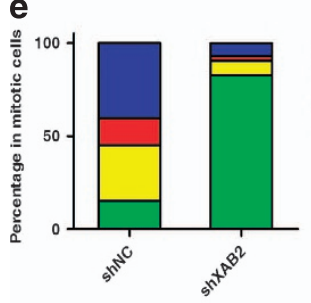

f
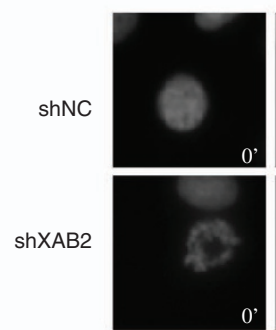

g

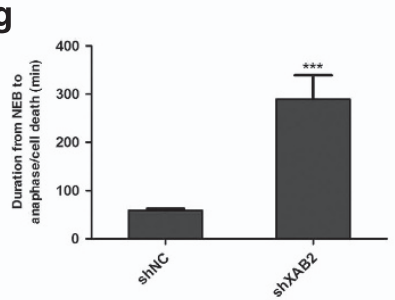

j

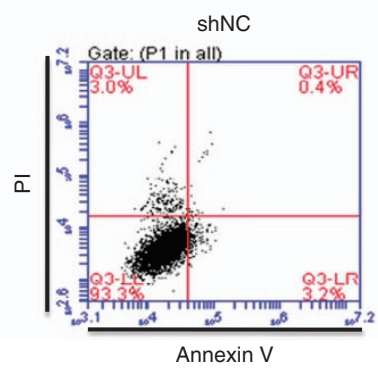
$\square$ Metaphase

$\square$ Anaphase

$\square$ Telophase

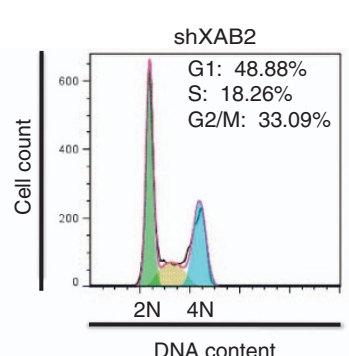

d

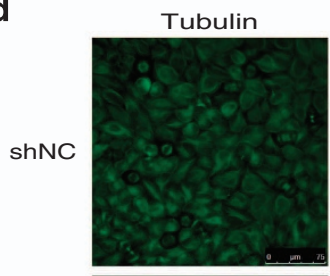

$\square$ Prophase/Prometaphase

$\operatorname{sh} \times A B 2$
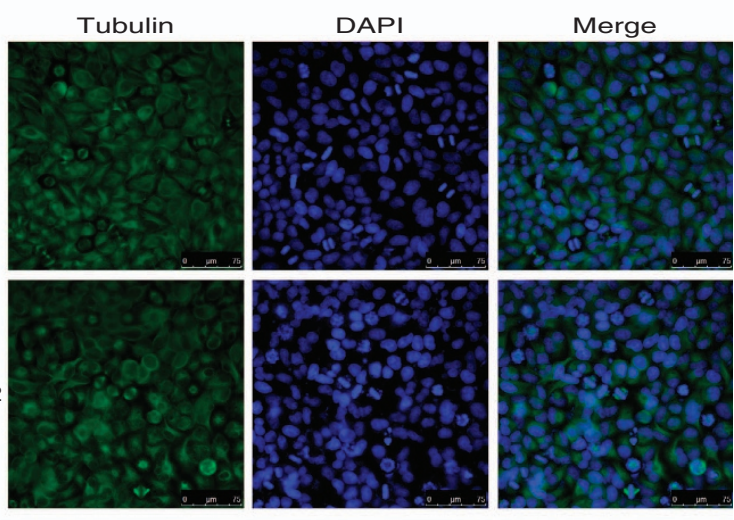

口s

G $2 / M$
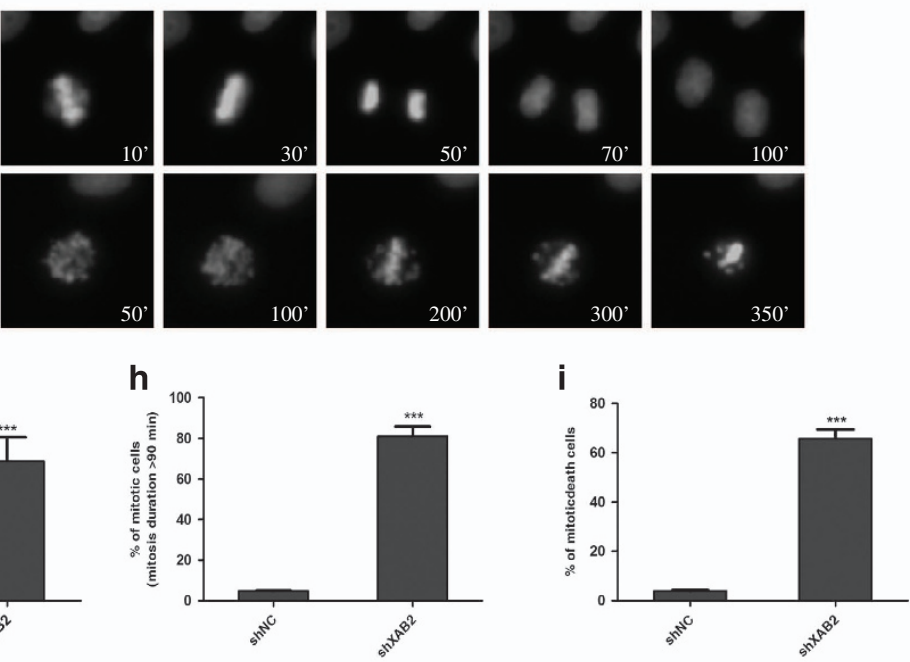

k
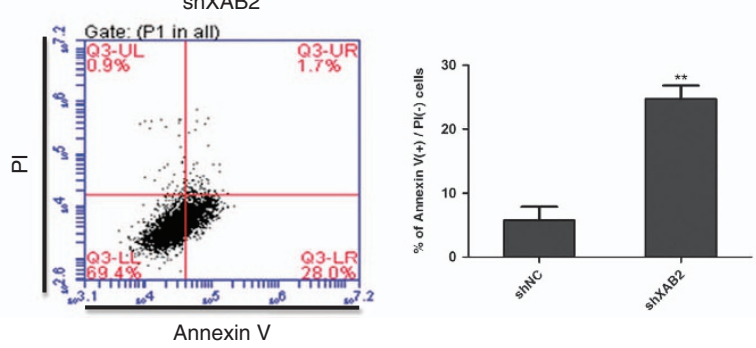
mitosis via CENPE. First, expression level of CENPE in XAB2 depleted cells was verified by RT-PCR and western blot analysis, the results indicated that XAB2 depletion led to a dramatic loss of CENPE in both mRNA and protein level (Figures 1c and 5a, Supplementary Figure S3). Whereas knockdown CENPE showed no effect on XAB2 protein a

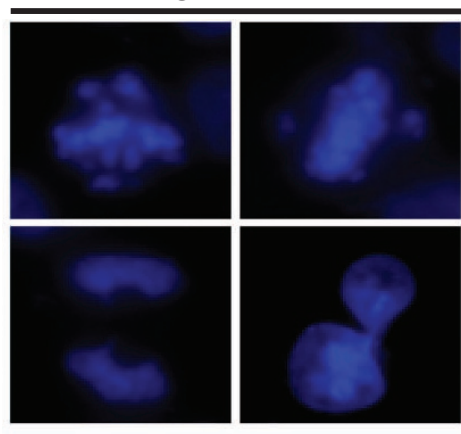

b
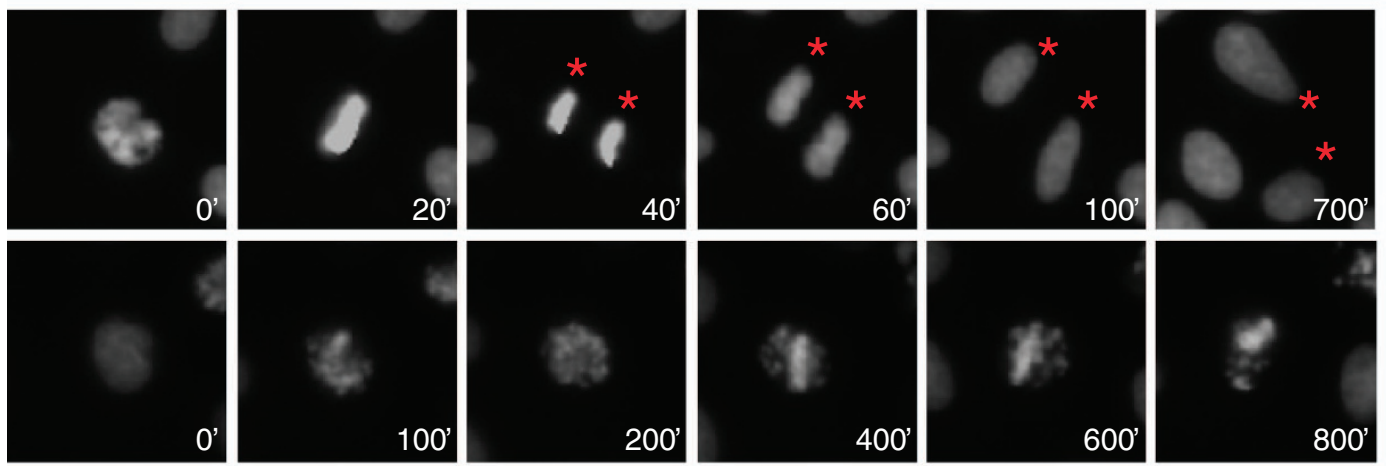

Mitotic arrest
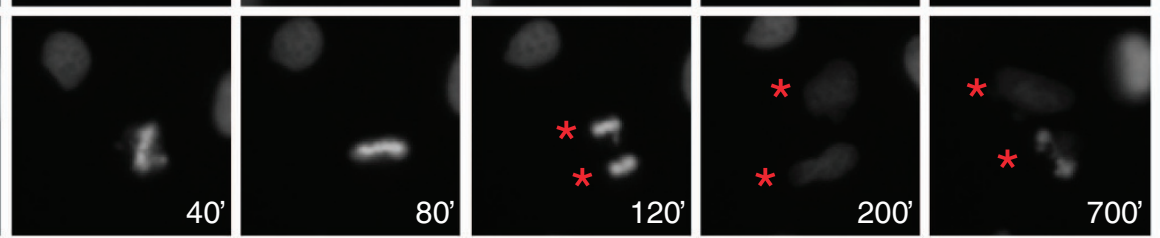

Mitotic delay
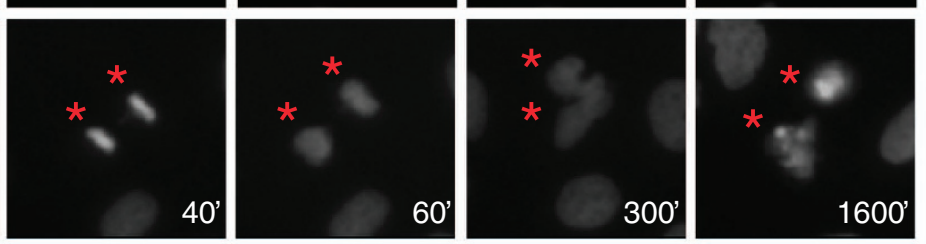

Normal

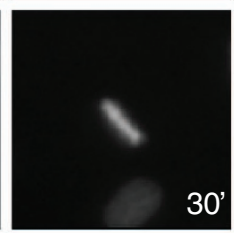

Figure 3 XAB2 knockdown leads to chromosome misalignment and missegregation. (a) Misaligned/missegregated chromosomes and internuclear bridges observed in XAB2-depleted cells. (b) Live cell imaging showing XAB2 knockdown resulted in mitotic arrest, mitotic delay and segregation defect. (c) Quantitation of mitotic cells after XAB2 depletion showed significant increase in mitotic arrest, mitotic delay and segregation defect

\footnotetext{
Figure 2 XAB2 deficiency causes mitotic arrest, mitotic catastrophe and cell death. (a) Depletion of XAB2 results in accumulation of G2/M cells by FACS analysis. Hela cells were transfected with control shRNA (shNC) or XAB2 shRNA (shXAB2) and then stained with PI for analysis of cell cycle distribution. (b) Quantitation of cells at different cell cycle phases after XAB2 depletion $(n=3) ;{ }^{* \star *} P \leq 0.001$. (c) Western blot reveals upregulation of CyclinB1 and Phospho-HistoneH3 (Ser10) in XAB2 depleted cells. (d) XAB2 knockdown induces significant increase of cells in prophase and prometaphase. Hela cells were transfected with control shRNA (shNC) or XAB2 shRNA (shXAB2) and then immunostained with $\alpha$-tubulin antibody and DAPI. (e) Quantitation of mitotic cells at different phases after XAB2 depletion. More than 100 randomly selected mitotic cells were counted $(n=3)$. (f) Live cell imaging showing XAB2 knockdown resulted in mitotic arrest and cell death. (g) Quantitation of average mitosis duration of GFP-H2B Hela cells with control or XAB2 knockdown ( $n=30$ cells); ${ }^{* \star} P \leq 0.001$ (NEB: nuclear envelop breakdown). (h) Quantitation of cells in mitotic arrest or mitotic delay (mitosis duration $>90$ min) as observed in live cell imaging. The mitosis duration is defined as the time lapse from nuclear envelop breakdown to anaphase onset or cell death; ${ }^{* * \star} P \leq 0.001$. (i) Quantitation of mitotic death cells after XAB2 depletion. More than 50 randomly selected mitotic cells were counted $(n=3) ;{ }^{* * *} P \leq 0.001$. (j) XAB2 knockdown causes apoptosis by FACS analysis using annexin V and PI staining. (k) Quantitation of annexin V-positive cells after XAB2 depletion $(n=3) ;{ }^{* *} P \leq 0.01$
} 
a
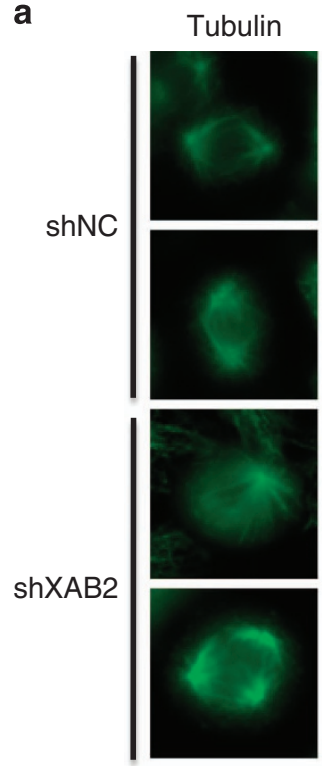

C
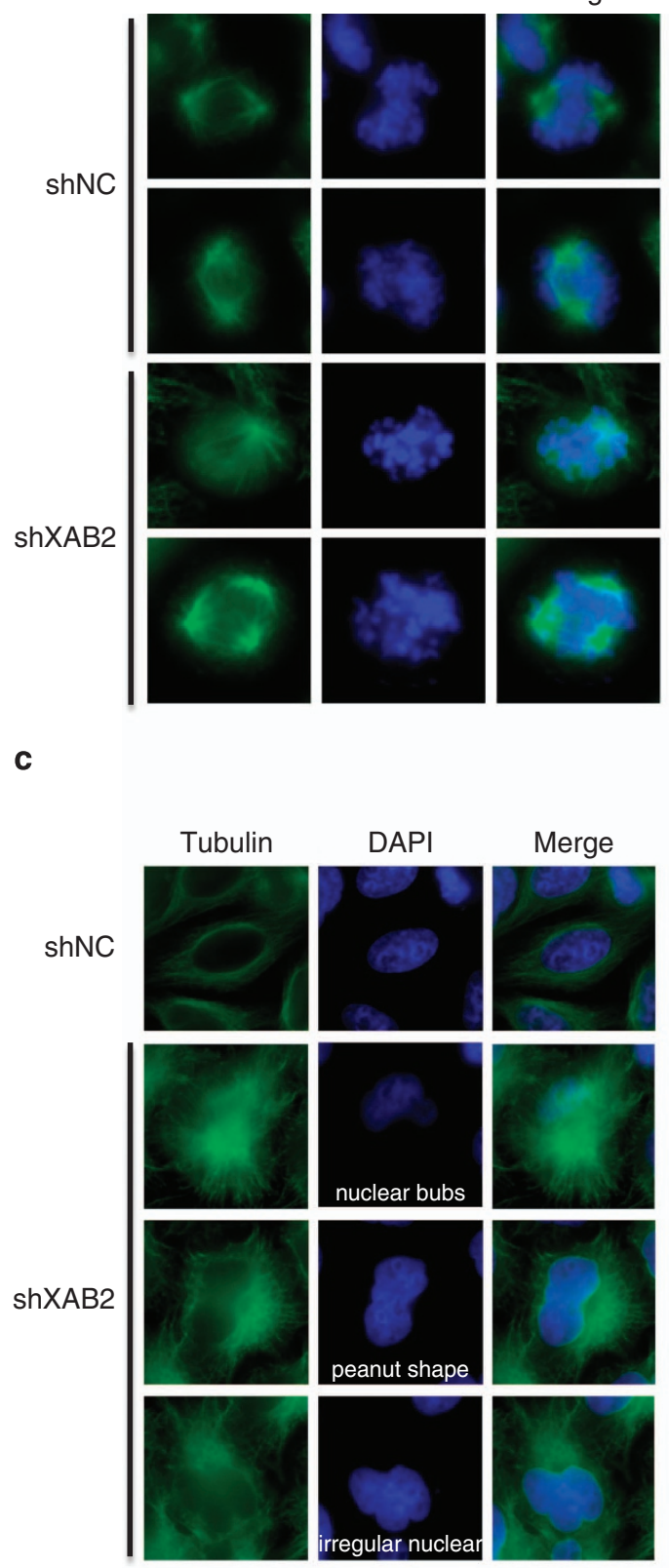

b

d

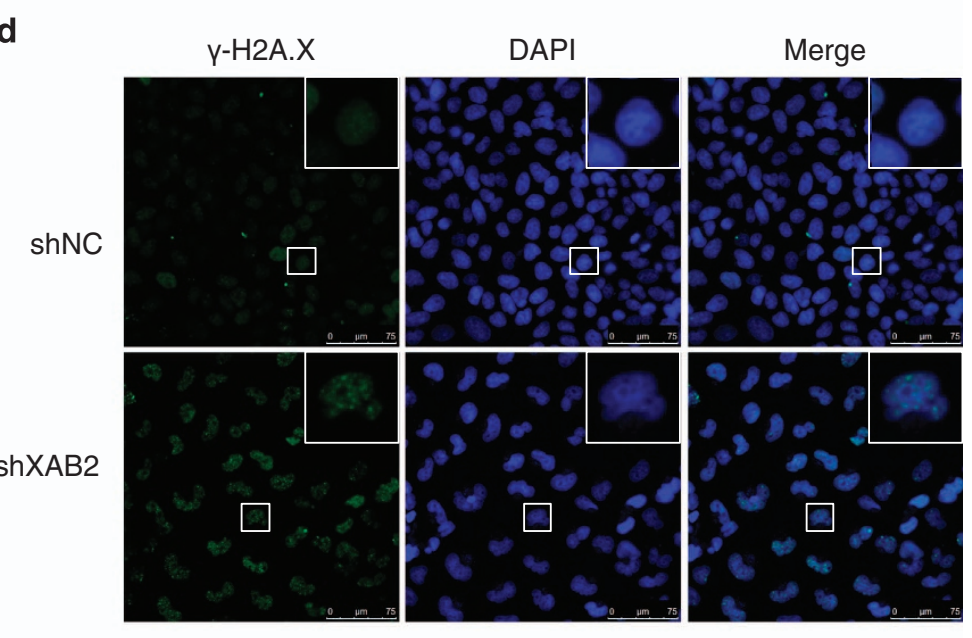

e

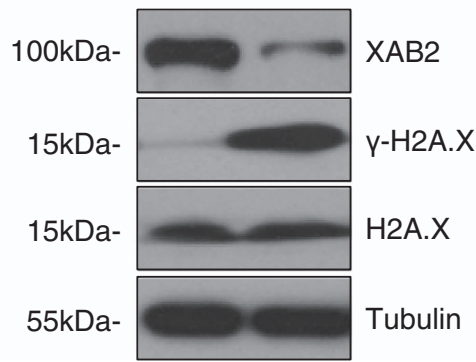

DAPI Merge
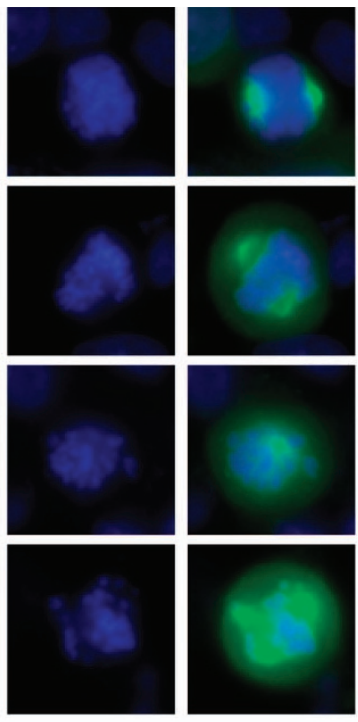

DAPI

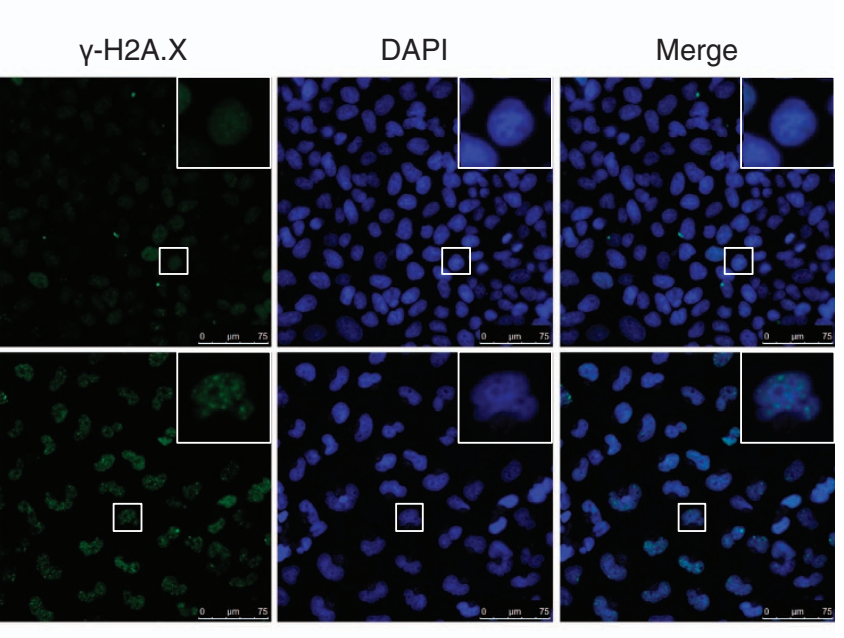

shNC shXAB2
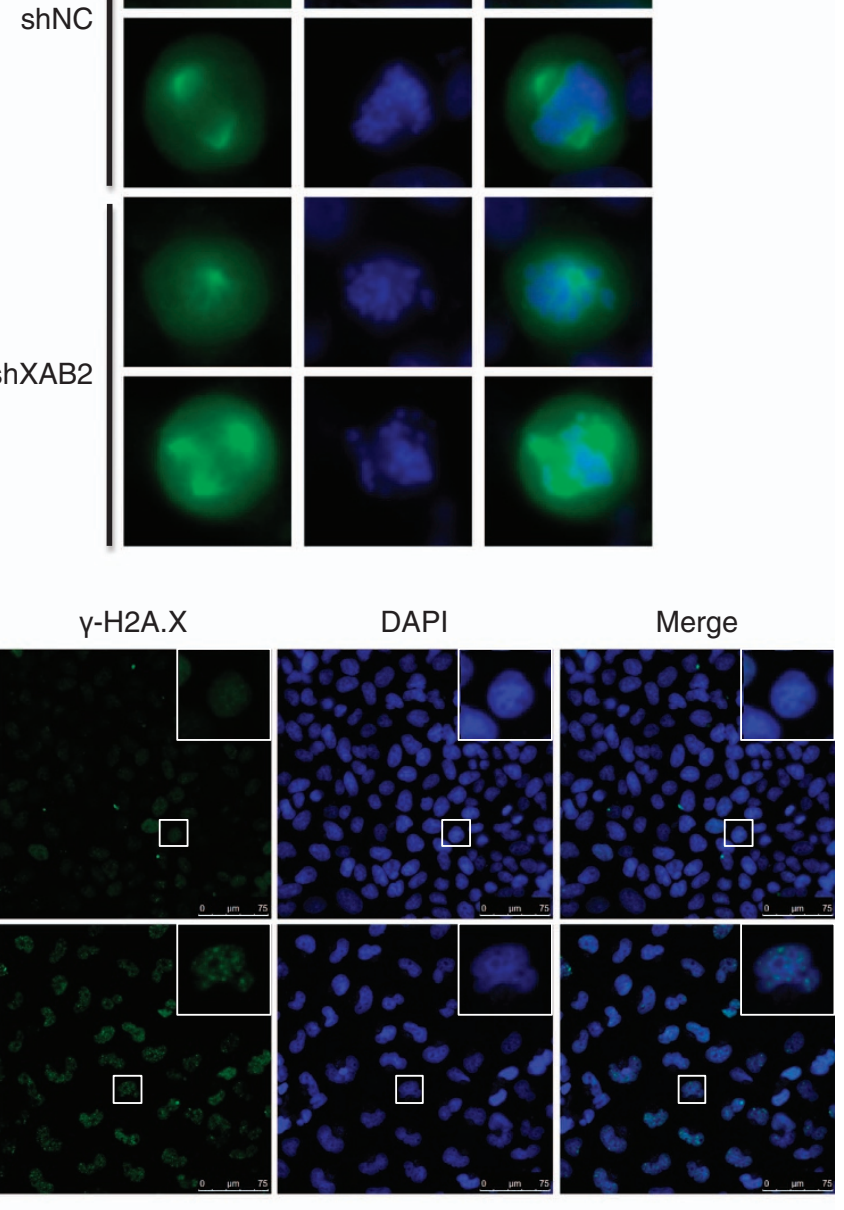

$\operatorname{shXAB2}$

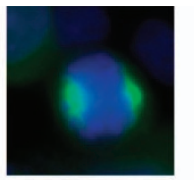

(1)
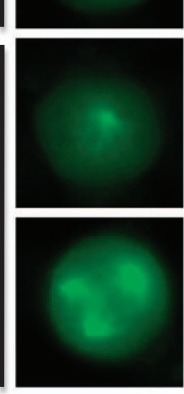

Figure 4 XAB2 knockdown results in aberrant spindle pole, disrupted microtubule organization and increased DNA damage. (a, b) Depletion of XAB2 leads to single or multiple spindle poles in prophase or prometaphase cells. Hela cells were transfected with control shRNA (shNC) or XAB2 shRNA (shXAB2) and then immunostained with $\alpha$-tubulin antibody (a) or Aurora A antibody (b) and DAPI. (c) Disrupted microtubule organization and nuclear structure in interphase cells after XAB2 knockdown. Hela cells were immunostained with $\alpha$-tubulin antibody (green) and DAPI (blue). (d) XAB2 knockdown results in increased DNA breaks as showed by immunostaining using $\gamma$-H2A.X antibody (green). (e) Western blot reveals upregulation of $\gamma$-H2A.X in XAB2 knockdown cells

expression, suggesting XAB2 functions upstream of CENPE (Figure 5b). Next, CENPE was depleted in HeLa cells using CENPE specific siRNA, the depletion led to $50.0 \%$ of cells arrested at G2/M phase compared to $19.0 \%$ in control
(Figures $5 \mathrm{c}$ and $\mathrm{d}, P<0.001$ ). Meanwhile, CENPE depletion also induced chromosome misalignment and prophase/ prometaphase arrest $(78.1 \%$ in knockdown cells versus $17.2 \%$ in control), similar to the phenotype observed in 
a

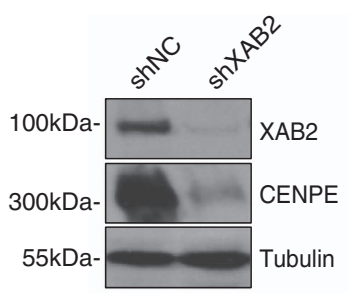

b

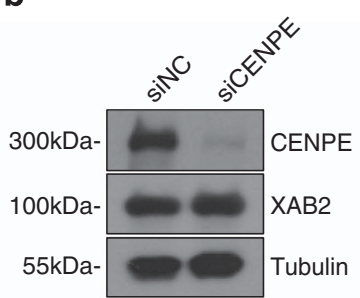

C

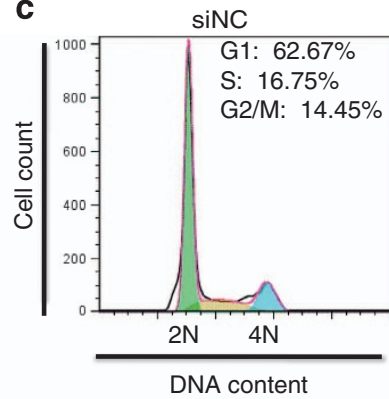

f

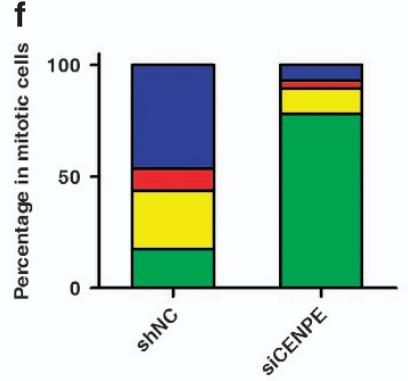

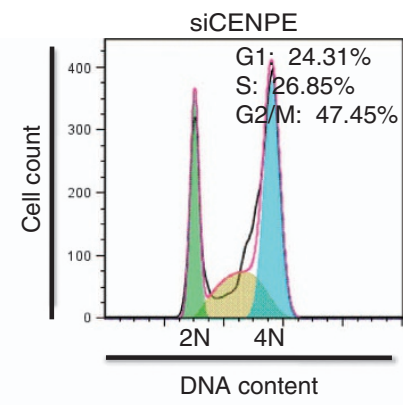

$\square$ Prophase/Prometaphase

Metaphase

$\square$ Anaphase

Telophase $\square$ G1

G2/M e
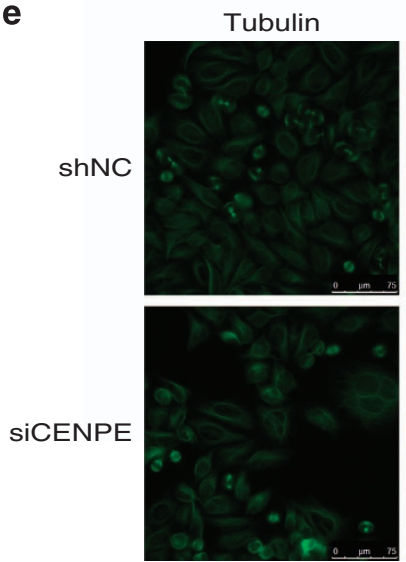
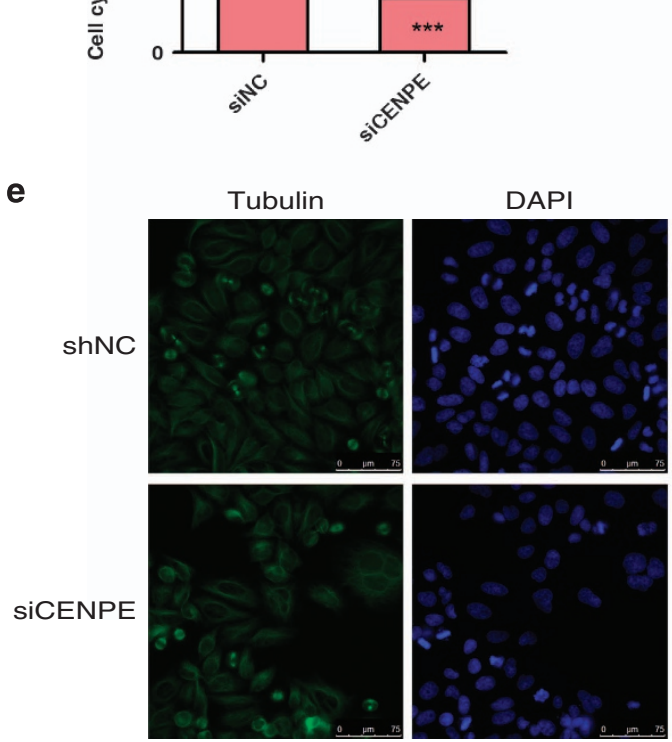

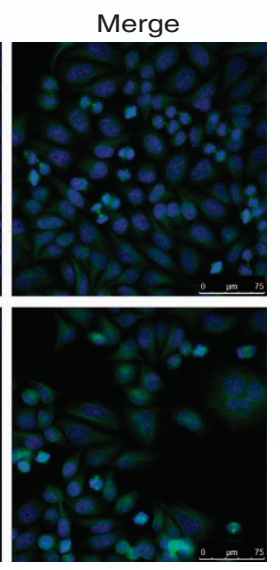

g

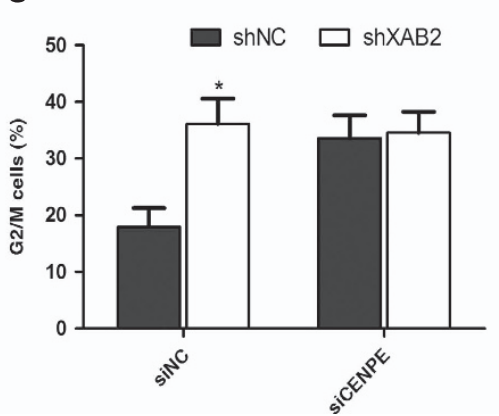

Figure 5 XAB2 regulates mitotic progression via CENPE. (a) Western blot showing decreased expression of CENPE protein in XAB2 knockdown cells. (b) Western blot showing knockdown of CENPE did not change the level of XAB2 protein. (c) CENPE knockdown leads to G2/M arrest as revealed by FACS analysis. Hela cells were transfected with control siRNA (siNC) or CENPE siRNA (siCENPE) and then stained with PI to analyse cell cycle distribution. (d) Quantitation of cells at different cell cycle phases after CENPE depletion $(n=3) ;{ }^{* * *} P \leq 0.001$. (e) Immunofluorescence staining shows significant increase of cells in prophase and prometaphase after CENPE knockdown. Hela cells were transfected with control siRNA (siNC) or CENPE siRNA (siCENPE) and then immunostained with $\alpha$-tubulin antibody and DAPI. (f) Quantitation of mitotic cells at different phases after CENPE depletion. More than 50 randomly selected mitotic cells were counted $(n=3)$. (g) CENPE knockdown followed by XAB2 shRNA treatment does not further increase G2/M arrest induced by CENPE depletion. $(n=3) ;{ }^{*} P \leqslant 0.05$

XAB2 deficiency cells (Figures $5 \mathrm{e}$ and f). To further confirm whether XAB2 regulates mitosis via CENPE, HeLa cells were treated with CENPE siRNA followed by depletion of XAB2. As shown in Figure 5g, CENPE knockdown alone dramatically arrested cells in G2/M phase, whereas CENPE knockdown followed by XAB2 shRNA treatment did not further enhance the G2/M arrest caused by CENPE, illustrating the important role of CENPE in the mitotic progression control induced by XAB2 depletion. Together, these results suggested that XAB2 regulated mitosis via CENPE.

XAB2 regulates CENPE expression at transcription level. We next investigated how XAB2 might regulate
CENPE expression. XAB2 was previously reported to interact with RNA polymerase II and play a role in transcription, ${ }^{1,6}$ moreover, we observed that depletion of XAB2 led to down-regulation of CENPE at mRNA level in this study, suggesting XAB2 may transcriptionally regulate the expression of CENPE. To test this, we first constructed a luciferase reporter that spanned a 1355-bp region from -1263 to +92 of transcription starting site of CENPE. As shown in Figure 6a, this region could drive the transcription of luciferase, suggesting it did serve as CENPE promoter. Overexpression of XAB2 increased CENPE promoter activity by 1.8-fold (Figure $6 \mathrm{a}$ ), whereas knockdown of CENPE resulted in a striking decrease of luciferase activity 


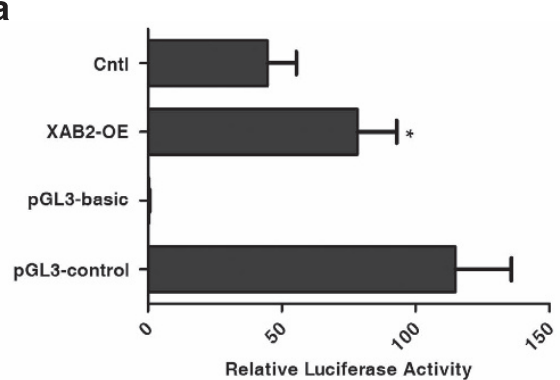

b

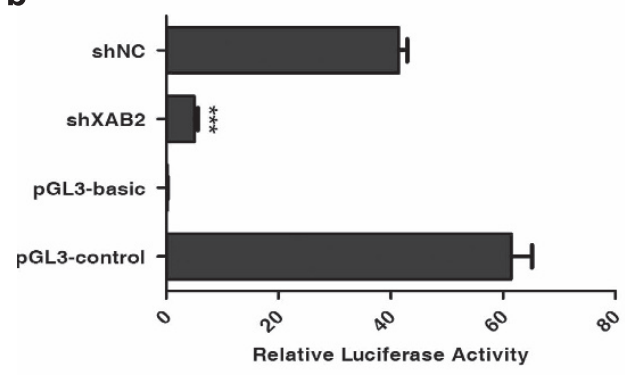

d

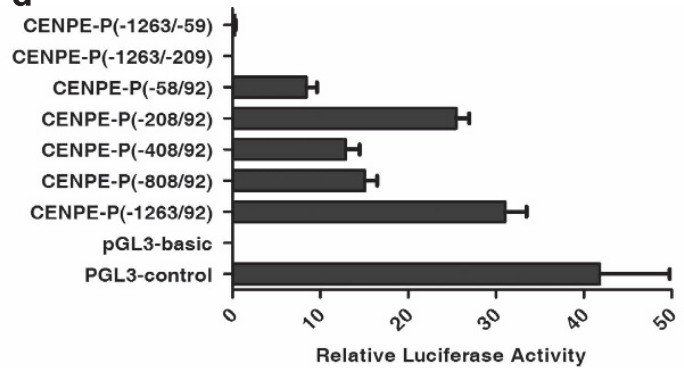

e

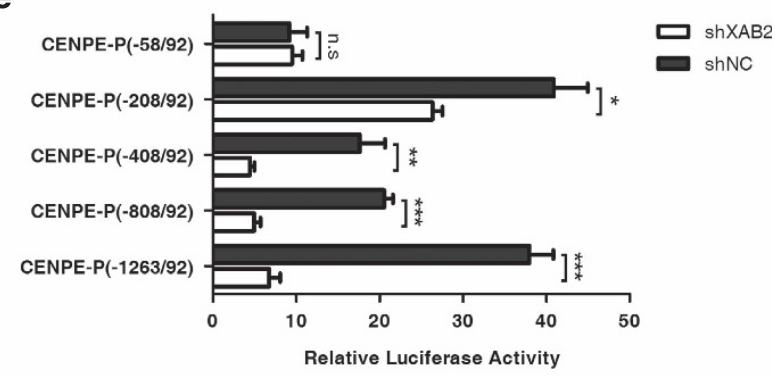

c

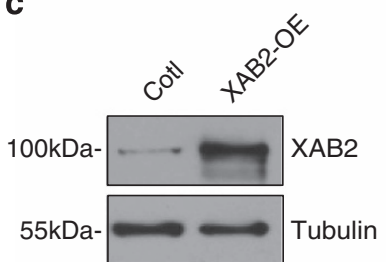

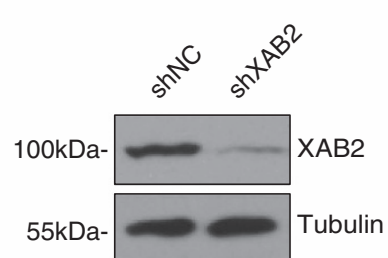

f

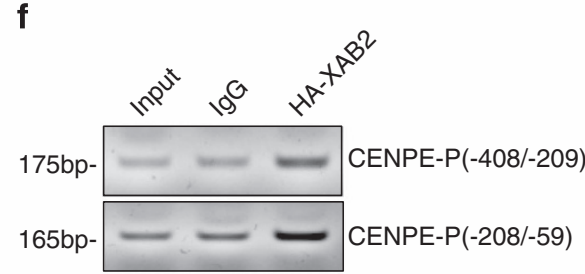

Figure 6 XAB2 regulates CENPE expression at transcriptional level. (a) Luciferase assay reveals that XAB2 overexpression increases CENPE promoter activity. Cntl: control, $\mathrm{OE}$ : over-expression $(n=3) ;{ }^{*} P \leqslant 0.05$. (b) Luciferase assay showing XAB2 knockdown decreases CENPE promoter activity. $(n=3) ;{ }^{* * *} P \leqslant 0.001$. (c) Western blot shows the overexpression and knockdown efficiency of XAB2. (d) Luciferase assay of serial deletion constructs of CENPE promoter leads to the identification of core region of CENPE promoter. (e) Effect of XAB2 knockdown on deletion constructs of CENPE promoter by luciferase assay $(n=3)$; n.s., no significance, ${ }^{*} P \leqslant 0.05,{ }^{* *} P \leqslant 0.01,{ }^{* \star *} P \leqslant 0.001$. (f) ChIP assay shows XAB2 interacts with CENPE promoter

by 7.2-fold (Figure 6b). The overexpression and knockdown efficiency of XAB2 were confirmed by western blot analysis (Figure 6c).

To identify the minimal region in CENPE promoter required for XAB2 regulation, we generated a series of deletion constructs. Transfection of these constructs into HeLa cells indicated that the region - 208/92 showed a luciferase activity close to the full length promoter (Figure 6d). Moreover, the region $-1263 /-209$ had no promoter activity (Figure $6 d$ ), suggesting the core promoter spans about $300 \mathrm{bp}$ from -208 to 92. Transfection of the deletion constructs followed by XAB2 knockdown revealed that $\mathrm{XAB} 2$ depletion resulted in striking decrease in luciferase activity for the full length promoter $-1263 / 92$, or deletion constructs $-808 / 92$ and $-408 / 92$, whereas further deletion $-208 / 92$ led to much less reduction and the decrease was abolished for $-58 / 92$ construct (Figure 6e), suggesting that the region between $-408 /-59$ is critical for the transcriptional regulation of CENPE expression by XAB2. Chromatin immunoprecipitation (ChIP) of HAtagged XAB2 protein also revealed significant enrichment of $\mathrm{XAB2}$ at CENPE promoter (Figure 6f). Altogether, these data support that XAB2 transcriptionally regulates the expression of CENPE.

\section{Discussion}

XAB2 is a component of Prp19 complex, it has been reported to function in transcription-coupled DNA repair, pre-mRNA splicing, mRNA export, transcription and homologous recombination. In this study, we reported a novel function of XAB2 as mitotic cell cycle regulator.

To gain deep insight into the impact of XAB2 deficiency, we performed microarray analysis on gene expression after XAB2 depletion in HeLa cells. Surprisingly, this analysis revealed that the expression of many genes functioning in cell cycle or mitosis regulation was changed significantly. We further showed that XAB2 deficiency induced chromosome misalignment and missegregation, abnormal nuclear structure, spindle pole, and microtubule organization, resulting in mitotic arrest, mitotic catastrophe and subsequent cell death, indicating a critical role of XAB2 in the regulation of mitotic cell cycle. Our results are consistent with phenotypes of XAB2 knockdown documented in the MITOCHECK database (www.mitocheck. org), including metaphase delay, metaphase alignment problems and cell deaths. ${ }^{25}$

In understanding how XAB2 affects mitotic cell cycle, CENPE turned out to be among the top genes with striking 
reduction in expression after knockdown of XAB2. CENPE is a plus end-directed kinetochore motor protein belonging to the kinesin-7 subfamily and has been extensively studied. It is first recruited at kinetochore during prometaphase depending on proteins such as BubR1, ${ }^{26} \mathrm{CENPF}^{26}{ }^{2}$ NUF2, ${ }^{27}$ SEPT7, ${ }^{28}$ TRAMM $^{29}$ and $\mathrm{CTCF}^{30}$ and then degraded by $\mathrm{APC} / \mathrm{C}$ and SCF at the end of mitosis. ${ }^{31,32}$ CENPE is a very large protein about $312 \mathrm{kDa}$ with multiple function domains, including an N-terminal ATP-dependent motor domain, a coiled-coil domain, a C-terminal kinetochore-binding domain and a C-terminal microtubule-binding domain. ${ }^{26,30}$ Previous work has suggested that CENPE plays an important role in the chromosome congression during prometaphase, ${ }^{33,34}$ the formation of stable attachment between spindle microtubules and kinetochores from prometaphase to anaphase, ${ }^{35,36}$ and the microtubule plus-end elongation. ${ }^{37}$ Furthermore, CENPE is also essential for regulating SAC, probably by modulating BubR1 activities. ${ }^{38-41}$ Downregulation of CENPE using various methods in different cell types and species consistently leads to chromosome misalignment and subsequent delayed mitotic progression. ${ }^{33,34,38,40,42-44}$ However, they show diverse cell fates, with some causing long-term mitotic arrest, ${ }^{40,42}$ some resulting in chromosome missegregation after a mitotic delay, ${ }^{38,43,44}$ and some even leading to cell death by apoptosis. ${ }^{33}$

Thus we tested the possibility that $\mathrm{XAB} 2$ regulates mitotic cell cycle via CENPE. Indeed, XAB2 depletion led to dramatic decrease of CENPE at both mRNA and protein levels. Consistent with previous reports, CENPE depletion resulted in similar phenotypes as observed for XAB2 knockdown, including chromosome misalignment and mitotic arrest. Furthermore, CENPE knockdown followed by XAB2 shRNA treatment did not change the G2/M arrest caused by CENPE. These results suggested that XAB2 functions upstream of CENPE and may regulate mitotic cell cycle progression via CENPE.

We further showed that XAB2 binds to the promoter of CENPE and regulates its expression using ChIP and luciferase assay. Overexpression of XAB2 led to higher luciferase activity whereas XAB2 depletion resulted in striking decrease of luciferase activity. Previous report showed that XAB2 interacts with RNA polymerase II and plays a role in transcription, mostly by modulating transcription elongation. ${ }^{6,10}$ Since XAB2 complex (hAquarius, XAB2, Prp19, CCDC16, hISY1 and PPIE) has been reported to bind to RNA but not DNA in vitro and XAB2 contains 15 tetratricopeptide repeat motifs involved in protein-protein interactions but without DNA-binding domains, it is very likely that XAB2 was recruited to the promoter of CENPE by other proteins.

However, in the CENPE rescue experiment, we observed no significant restoration of cell cycle arrest when CENPE was re-expressed after XAB2 depletion (data not shown). Intriguingly, re-expression of CENPE after its own knockdown in Hela cells could not reverse cell cycle arrest either (data not shown). Possible explanation for these observations may include that the overexpression level is not high enough to compensate the depletion due to the high molecular weight of CENPE $(312 \mathrm{kDa})$, or the phenotype induced by CENPE deficiency is severe and irreversible. In addition, we cannot exclude the possibility that the effect of XAB2 depletion is mediated by defects in multiple genes as revealed by microarray analysis that a subset of genes involving in cell cycle and mitotic progression are down-regulated.

Mitosis is one of the critical processes in cell cycle for proper chromosome segregation during cell division. Mitosis dysregulation often causes genome instability or aneuploidy, leads to mitotic catastrophe and cell death, and is closely associated with cancers and many other diseases. Thus, targeting mitosis has been proposed as an attractive therapeutic strategy for cancer therapy, ${ }^{45,46}$ for example, CENPE inhibitor like GSK923295, ${ }^{47}$ syntelin ${ }^{48}$ or PF $2721^{49}$ is now considered to have antitumour activity. Therefore, it will be interesting to investigate whether XAB2 can serve as a new anti-mitotic target for cancer therapy.

\section{Materials and Methods}

Constructs and antibodies. XAB2 construct was purchased from Origene and re-cloned into modified pcDNA3.1 vector (Promega, USA) containing HA tag at the $5^{\prime}$ end. A $1355 \mathrm{bp}$ fragment of $5^{\prime}$ region sequence extending from -1263 to 92 ( +1 is the transcription start site) of human CENPE gene was amplified by PCR from Hela genomic DNA and cloned into pGL3-Basic vector (Promega) at Kpnl/ Hindlll sites. Deletion constructs of CENPE promoter were amplified from the full length promoter construct using nested PCR. The sequences of all the constructs were confirmed by direct sequencing. Primer sequences are listed in Supplementary Table 2.

Polyclonal antibody against XAB2 (Proteintech, Wuhan, China, $1: 800$ ), PhosphoHistone H3 (Ser10) (CST, MA, USA, 1:1000), Cdc2 (CST, 1:2000), Histone H2A.X (Proteintech, 1:1000), Phospho-Histone H2A.X ( $\gamma$-H2A.X) (CST, 1:800), monoclonal antibodies against HA tag (Covance, MA, USA, 1:2000), CyclinB1 (CST, 1:2000), CENPE (Abcam, MA, USA, 1:1000), and $\alpha$-tubulin (Sigma, Germany, 1:5000) were used in western blots.

Cell culture and RNA interference. HeLa and 293T cells were gifts from Reed Lab in Harvard Medical School, MDA-MB-231 cells were purchased from the American Type Culture Collection (Manassas, VA, USA). All the cells were cultured in dulbecco's modified eagle medium supplemented with $10 \%$ fetal bovine serum.

For siRNA mediated gene knockdown, cells were plated in six-well plate and $2 \mu \mathrm{l}$ siRNA at $50 \mu \mathrm{M}$ were transfected using Lipofectamine 3000 . Cells were treated with CENPE siRNA or XAB2 siRNA for analysis 24 or $55 \mathrm{~h}$, respectively, after transfection. CENPE siRNA and XAB2 siRNA were previously reported, ${ }^{22,50}$ non-target siRNA (RiboBio, China) was used as negative control. The siRNA sequences are as follows: CENPE SIRNA (5'-CCACUAGAGUUGAAAGAUAdTdT-3'), XAB2-siRNA-1 (5'-CCAAUUCUCUGUCAAAUGCdTdT-3'), XAB2-siRNA-2 (5'-ACGCAGCACUCU CGAAUUUdTdT-3').

For shRNA mediated gene knockdown, lentiviruses expressing XAB2 shRNA were produced as following: 293T cells were placed in $6 \mathrm{~cm}$ dish and cotransfected with $1.4 \mu \mathrm{g}$ of XAB2 shRNA (cloned in PLKO.1), $1.4 \mu \mathrm{g}$ of pREV, $1.4 \mu \mathrm{g}$ of pGag/Pol/PRE and $0.7 \mu \mathrm{g}$ of pVSVG. For control, replace XAB2 shRNA construct with control vector. Six hours after transfection, the mixture was replaced by fresh dulbecco's modified eagle medium containing 10\% FBS and cells were cultured for an additional $48 \mathrm{~h}$. Then the medium containing lentiviruses was filtered and stored at $-80^{\circ} \mathrm{C}$. As for lentivirus infection, cells grown in six-well plate were infected twice with lentivirus containing $6 \mu \mathrm{g} / \mathrm{ml}$ polybrene for a total of $48 \mathrm{~h}$. For microarray, western blot, immunofluorescence, RT-PCR and cell cycle distribution analysis, cells were harvested after culture in fresh medium for another $24 \mathrm{~h}$. For cell death analysis, cells were harvested $48 \mathrm{~h}$ later. The full sequence of XAB2 shRNA-1 and XAB2 shRNA-2 are CCGGGCTTCGCTACATCGAGTTCAACTCGAGTTGAA CTCGATGTAGCGAAGCTTTTTG and CCGGGCAGTATGACATGTTCAACATCTCG AGATGTTGAACATGTCATACTGCTTTTTG, respectively. XAB2 shRNA-1 was used in the XAB2 knockdown experiments in this study unless otherwise indicated.

Microarray gene expression analysis. Hela cells were plated in six-well plate and infected twice with control or XAB2 shRNA lentivirus. Then cells were harvested and total RNA was isolated using RNeasy plus kit (Qiagen, Germany) 
following the manufacturer's instruction. The integrity of total RNA was monitored with Agilent 2100 Bioanalyzer. Microarrays were performed using Human Transcriptome Array 2.0 (Affymetrix, USA) with three independent experiments. Results were analysed by using the Transcriptome Analysis Console from Affymetrix. Only genes that had a 2-fold increase or decrease in expression with a significance of $P<0.05$ were included in the final results. Functional analysis of the genes with expression significantly changed by XAB2 knockdown was performed using Gene Ontology analysis.

FACS analysis. To examine the cell cycle distribution, cells were harvested and fixed in $75 \%$ ethanol at $4^{\circ} \mathrm{C}$ overnight, washed twice with PBS, and then incubated with PI (Sigma) solution containing RNase for $30 \mathrm{~min}$. The flow cytometry analysis was conducted on ACCURIC6, and the data were analysed using FlowJo7.6 software.

For cell death analysis, cells were stained using annexin/PI staining kit (KeyGEN BioTECH, Nanjing, China) for detection according to the manufacturer's instructions.

To detect the fraction of phospho-Histone $\mathrm{H} 3 \mathrm{Ser} 10$ positive cells, cells were fixed by $75 \%$ ethanol, permeabilized by $0.25 \%$ Triton $X-100$, and then stained with Alexa Fluor488-conjugated phospho-Histone H3 Ser10 antibody (1:50, CST) and $\mathrm{PI}$.

Immunofluorescence. Cells were grown in $35 \mathrm{~mm}$ cell culture dish with glass bottom (NEST, Wuxi, China), fixed with 4\% paraformaldehyde (Sigma, Germany) for $30 \mathrm{~min}$, followed by permeabilization with $0.5 \%$ Triton X-100 for $10 \mathrm{~min}$ at room temperature. Cells were then incubated with $\alpha$-tubulin antibody (1:250) diluted in PBS with $10 \%$ calf serum at $4{ }^{\circ} \mathrm{C}$ overnight, and immunostained with Alexa 488 labeled anti-mouse antibody (1:500) diluted in the same buffer at room temperature for $30 \mathrm{~min}$, followed by DAPI staining and four washes with PBS for $5 \mathrm{~min}$ each. Fluorescence was detected using DMI6000 microscope (Leica, Germany).

Live cell imaging. GFP-H2B HeLa cells were a gift from Dr Huiyan Li in China National Center of Biomedical Analysis and were placed in $35 \mathrm{~mm}$ cell culture dish with glass bottom (NEST). Twenty-four hours after second infection with control or XAB2 shRNA lentivirus, images were captured every 10 min for $48 \mathrm{~h}$ using DMI6000 microscope (Leica) equipped with a $\times 40$ objective lens in a chamber maintained at $37{ }^{\circ} \mathrm{C}$ with $5 \% \mathrm{CO}_{2}$.

Transfection and luciferase assay. Cells were seeded into 12-well plate the day before transfection. $1 \mu \mathrm{g}$ of firefly luciferase constructs were transfected using lipofectamine 2000. The pRL-TK plasmid (100 ng/sample) encoding Renilla luciferase was cotransfected, and the readout was used for normalization of firefly luciferase activity. Cells were harvested $24 \mathrm{~h}$ after transfection and luciferase activity was measured with Dual-Luciferase Reporter Assay Kit (Promega). All transfections were performed in triplicate.

To assess the effect of XAB2 overexpression or knockdown on CENPE promoter activity, Hela cells in 12-well plates were transfected with XAB2 construct for $24 \mathrm{~h}$ or infected twice with lentivirus containing XAB2 shRNA, followed by co-transfection of CENPE promoter construct and pRL-TK vector, cells were then harvested after $24 \mathrm{~h}$ for the measurement of luciferase activity.

ChIP. The ChIP assay was performed using EpiQuik Chromatin Immunoprecipitation Kit from Epigentek Group Inc. (Brooklyn, NY, USA) according to the manufacturer's protocol. Protein-DNA complexes were immunoprecipitated with HA antibody, and normal mouse IgG was used as negative control. Primer sets for CENPE were shown in Supplementary Table 2.

Statistics. Data were presented as mean \pm s.d. (standard deviation). Statistical analyses between two groups were performed using Student's $t$-test with statistical significance defined as ${ }^{*} P<0.05,{ }^{* *} P<0.01$ and ${ }^{* *} P<0.001$.

\section{Conflict of Interest}

The authors declare no conflict of interest.

Acknowledgements. We thank Dr Don W. Cleveland for providing the fulllength human CENPE plasmid, and Dr Huiyan Li for GFP-H2B HeLa cells. This work was supported by National Natural Science Foundation of China (Grant 81472491), Liaoning Pandeng Scholar Program and Innovative Research Team in University, Ministry of Education, China (No.IRT13049).
1. Nakatsu $Y$, Asahina H, Citterio E, Rademakers S, Vermeulen W, Kamiuchi S et al. XAB2, a novel tetratricopeptide repeat protein involved in transcription-coupled DNA repair and transcription. J Biol Chem 2000; 275: 34931-34937.

2. Ben-Yehuda S, Dix I, Russell CS, McGarvey M, Beggs JD, Kupiec M. Genetic and physical interactions between factors involved in both cell cycle progression and pre-mRNA splicing in Saccharomyces cerevisiae. Genetics 2000; 156: 1503-1517.

3. Russell CS, Ben-Yehuda S, Dix I, Kupiec M, Beggs JD. Functional analyses of interacting factors involved in both pre-mRNA splicing and cell cycle progression in Saccharomyces cerevisiae. Rna 2000; 6: 1565-1572.

4. Amada N, Tezuka T, Mayeda A, Araki K, Takei N, Todokoro K et al. A novel rat orthologue and homologue for the Drosophila crooked neck gene in neural stem cells and their immediate descendants. J Biochem 2003; 133: 615-623.

5. Guilgur LG, Prudêncio P, Sobral D, Liszekova D, Rosa A, Martinho RG et al. Requirement for highly efficient pre-mRNA splicing during Drosophila early embryonic development. eLife 2014; 3: e02181.

6. Kuraoka I, Ito S, Wada T, Hayashida M, Lee L, Saijo M et al. Isolation of XAB2 complex involved in pre-mRNA splicing, transcription, and transcription-coupled repair. J Biol Chemistry 2008; 283: 940-950.

7. Fousteri M, Vermeulen W, van Zeeland AA, Mullenders LH. Cockayne syndrome A and B proteins differentially regulate recruitment of chromatin remodeling and repair factors to stalled RNA polymerase II in vivo. Mol cell 2006; 23: 471-482.

8. Deckert J, Hartmuth K, Boehringer D, Behzadnia N, Will CL, Kastner B et al. Protein composition and electron microscopy structure of affinity-purified human spliceosomal B complexes isolated under physiological conditions. Mol Cell Biol 2006; 26: 5528-5543.

9. Chan SP, Kao DI, Tsai WY, Cheng SC. The Prp19p-associated complex in spliceosome activation. Science 2003; 302: 279-282.

10. Chanarat S, Strasser K. Splicing and beyond: the many faces of the Prp19 complex. Biochimica et biophysica acta 2013; 1833: 2126-2134.

11. Chanarat S, Seizl M, Strasser K. The Prp19 complex is a novel transcription elongation factor required for TREX occupancy at transcribed genes. Genes Dev 2011; 25: 1147-1158.

12. Yonemasu R, Minami M, Nakatsu Y, Takeuchi M, Kuraoka I, Matsuda Y et al. Disruption of mouse XAB2 gene involved in pre-mRNA splicing, transcription and transcription-coupled DNA repair results in preimplantation lethality. DNA Repair 2005; 4: 479-491.

13. Ohnuma-Ishikawa K, Morio T, Yamada T, Sugawara Y, Ono M, Nagasawa M et al. Knockdown of XAB2 enhances all-trans retinoic acid-induced cellular differentiation in all-trans retinoic acidsensitive and -resistant cancer cells. Cancer Res 2007; 67: 1019-1029.

14. Chang W, Ma L, Lin L, Gu L, Liu X, Cai H et al. Identification of novel hub genes associated with liver metastasis of gastric cancer. Int J Cancer [Journal international du cancer] 2009; 125: 2844-2853.

15. Ossovskaya V, Wang $Y$, Budoff $A, X u Q$, Lituev A, Potapova $O$ et al. Exploring molecular pathways of triple-negative breast cancer. Genes Cancer 2011; 2: 870-879.

16. Sredni ST, Huang CC, Pundy T, Patel K, Halpern AL, Grupenmacher AT et al. A gene signature for a long-term survivor of an atypical teratoid/rhabdoid tumor. Cancer Genet 2014; 207: 420-424.

17. Bonome T, Levine DA, Shih J, Randonovich M, Pise-Masison CA, Bogomolniy $F$ et al. A gene signature predicting for survival in suboptimally debulked patients with ovarian cancer. Cancer Res 2008; 68: 5478-5486.

18. Barretina J, Taylor BS, Banerji S, Ramos AH, Lagos-Quintana M, Decarolis PL et al. Subtype-specific genomic alterations define new targets for soft-tissue sarcoma therapy. Nat Genet 2010; 42: 715-721

19. Pei N, Cao L, Liu Y, Wu J, Song Q, Zhang Z et al. XAB2 tagSNPs contribute to non-small cell lung cancer susceptibility in Chinese population. BMC Cancer 2015; 15: 560.

20. Chambers SM, Shaw CA, Gatza C, Fisk CJ, Donehower LA, Goodell MA et al. Aging hematopoietic stem cells decline in function and exhibit epigenetic dysregulation. PLOS Biol 2007; 5: e201.

21. Lei H, Zhai B, Yin S, Gygi S, Reed R. Evidence that a consensus element found in naturally intronless mRNAs promotes mRNA export. Nucleic Acids Res 2013; 41: 2517-2525.

22. Onyango DO, Howard SM, Neherin K, Yanez DA, Stark JM. Tetratricopeptide repeat factor XAB2 mediates the end resection step of homologous recombination. Nucleic Acids Res 2016; 44: 5702-5716.

23. Fenech M, Crott JW. Micronuclei, nucleoplasmic bridges and nuclear buds induced in folic acid deficient human lymphocytes-evidence for breakage-fusion-bridge cycles in the cytokinesis-block micronucleus assay. Mutat Res 2002; 504: 131-136.

24. Fenech M, Kirsch-Volders M, Natarajan AT, Surralles J, Crott JW, Parry J et al. Molecular mechanisms of micronucleus, nucleoplasmic bridge and nuclear bud formation in mammalian and human cells. Mutagenesis 2011; 26: 125-132.

25. Neumann B, Walter T, Hériché JK, Bulkescher J, Erfle H, Conrad C et al. Phenotypic profiling of the human genome by time-lapse microscopy reveals cell division genes. Nature 2010; 464: 721-727.

26. Chan GK, Schaar BT, Yen TJ. Characterization of the kinetochore binding domain of CENP-E reveals interactions with the kinetochore proteins CENP-F and hBUBR1. J Cell Biol 1998; 143: 49-63.

27. Liu D, Ding X, Du J, Cai X, Huang Y, Ward T et al. Human NUF2 interacts with centromereassociated protein $E$ and is essential for a stable spindle microtubule-kinetochore attachment. J Biol Chem 2007; 282: 21415-21424. 
28. Zhu M, Wang F, Yan F, Yao PY, Du J, Gao X et al. Septin 7 interacts with centromereassociated protein $\mathrm{E}$ and is required for its kinetochore localization. J Biol Chem 2008; 283: 18916-18925.

29. Milev MP, Hasaj B, Saint-Dic D, Snounou S, Zhao Q, Sacher M. TRAMM/TrappC12 plays a role in chromosome congression, kinetochore stability, and CENP-E recruitment. J Cell Biol 2015; 209: 221-234.

30. Xiao T, Wongtrakoongate P, Trainor C, Felsenfeld G. CTCF recruits centromeric protein CENP-E to the pericentromeric/centromeric regions of chromosomes through unusual CTCF-binding sites. Cell Rep 2015; 12: 1704-1714

31. Brown KD, Coulson RM, Yen TJ, Cleveland DW. Cyclin-like accumulation and loss of the putative kinetochore motor CENP-E results from coupling continuous synthesis with specific degradation at the end of mitosis. J Cell Biol 1994; 125: 1303-1312.

32. Liu D, Zhang N, Du J, Cai X, Zhu M, Jin C et al. Interaction of Skp1 with CENP-E at the midbody is essential for cytokinesis. Biochem Biophys Res Commun 2006; 345: 394-402.

33. Schaar BT, Chan GK, Maddox P, Salmon ED, Yen TJ. CENP-E function at kinetochores is essential for chromosome alignment. J Cell Biol 1997; 139: 1373-1382.

34. Wood KW, Sakowicz R, Goldstein LS, Cleveland DW. CENP-E is a plus end-directed kinetochore motor required for metaphase chromosome alignment. Cell 1997; 91: 357-366.

35. Gudimchuk N, Vitre B, Kim Y, Kiyatkin A, Cleveland DW, Ataullakhanov Fl et al. Kinetochore kinesin CENP-E is a processive bi-directional tracker of dynamic microtubule tips. Nat Cell Biol 2013; 15: 1079-1088.

36. Vitre B, Gudimchuk N, Borda R, Kim Y, Heuser JE, Cleveland DW et al. Kinetochoremicrotubule attachment throughout mitosis potentiated by the elongated stalk of the kinetochore kinesin CENP-E. Mol Biol Cell 2014; 25: 2272-2281.

37. Sardar HS, Luczak VG, Lopez MM, Lister BC, Gilbert SP. Mitotic kinesin CENP-E promotes microtubule plus-end elongation. Curr Biol 2010; 20: 1648-1653.

38. Weaver BA, Bonday ZQ, Putkey FR, Kops GJ, Silk AD, Cleveland DW. Centromere associated protein- $E$ is essential for the mammalian mitotic checkpoint to prevent aneuploidy due to single chromosome loss. J Cell Biol 2003; 162: 551-563.

39. Abrieu A, Kahana JA, Wood KW, Cleveland DW. CENP-E as an essential component of the mitotic checkpoint in vitro. Cell 2000; 102: 817-826.

40. Yao X, Abrieu A, Zheng Y, Sullivan KF, Cleveland DW. CENP-E forms a link between attachment of spindle microtubules to kinetochores and the mitotic checkpoint. Nat Cell Biol 2000; 2: 484-491.

41. Mao Y, Abrieu A, Cleveland DW. Activating and silencing the mitotic checkpoint through CENP-E-dependent activation/inactivation of BubR1. Cell 2003; 114: 87-98.

42. McEwen BF, Chan GK, Zubrowski B, Savoian MS, Sauer MT, Yen TJ. CENP-E is essential for reliable bioriented spindle attachment, but chromosome alignment can be achieved via redundant mechanisms in mammalian cells. Mol Biol Cell 2001; 12: 2776-2789.
43. Putkey FR, Cramer T, Morphew MK, Silk AD, Johnson RS, Mclntosh JR et al. Unstable kinetochore-microtubule capture and chromosomal instability following deletion of CENP-E. Dev Cell 2002; 3: 351-365.

44. Tanudji M, Shoemaker J, L'Italien L, Russell L, Chin G, Schebye XM. Gene silencing of CENP-E by small interfering RNA in HeLa cells leads to missegregation of chromosomes after a mitotic delay. Mol Biol Cell 2004; 15: 3771-3781.

45. Chan KS, Koh CG, Li HY. Mitosis-targeted anti-cancer therapies: where they stand. Cell Death Dis 2012; 3: e411.

46. Manchado E, Guillamot M, Malumbres M. Killing cells by targeting mitosis. Cell Death Differ 2012; 19: 369-377.

47. Wood KW, Lad L, Luo L, Qian X, Knight SD, Nevins N et al. Antitumor activity of an allosteric inhibitor of centromere-associated protein-E. Proc Natl Acad Sci USA 2010; 107: 5839-5844.

48. Ding $X$, Yan F, Yao $P$, Yang $Z$, Wan $W$, Wang $X$ et al. Probing CENP-E function in chromosome dynamics using small molecule inhibitor syntelin. Cell Res 2010; 20: 1386-1389.

49. Kung PP, Martinez R, Zhu Z, Zager M, Blasina A, Rymer I et al. Chemogenetic evaluation of the mitotic kinesin CENP-E reveals a critical role in triple-negative breast cancer. Mol Cancer Ther 2014; 13: 2104-2115

50. Kim Y, Holland AJ, Lan W, Cleveland DW. Aurora kinases and protein phosphatase 1 mediate chromosome congression through regulation of CENP-E. Cell 2010; 142: 444-455.

(c) Cell Death and Disease is an open-access journal published by Nature Publishing Group. This work is licensed under a Creative Commons Attribution 4.0 International License. The images or other third party material in this article are included in the article's Creative Commons license, unless indicated otherwise in the credit line; if the material is not included under the Creative Commons license, users will need to obtain permission from the license holder to reproduce the material. To view a copy of this license, visit http://creativecommons.org/licenses/by/4.0/

(C) The Author(s) 2016

Supplementary Information accompanies this paper on Cell Death and Disease website (http://www.nature.com/cddis) 